\title{
A Educação Ambiental por meio da ludicidade: uma proposta didática
}

\author{
Environmental Education by ludicity: a didactical proposal
}

\author{
Carine Leal Klein ${ }^{1}$ \\ Aline Locatelli ${ }^{2}$ \\ Alana Neto Zoch ${ }^{3}$
}

\section{Resumo}

O presente texto refere-se a um estudo desenvolvido na forma de intervenção didática realizada na disciplina de Ciências, especificamente sobre a temática Educação Ambiental, com uma turma de quinto ano do ensino fundamental. A questão central do estudo foi verificar em que medida uma intervenção didática estruturada por meio de atividades lúdicas pode estimular os educandos a refletir sobre as causas, consequências e possíveis soluções para os problemas ambientais de sua comunidade. Os dados para elaboração da sequência didática - estruturada a partir de atividade lúdicas - foram obtidos por meio de um questionário inicial que visou a identificar os principais problemas ambientais enfrentados pelos alunos. A pertinência de tal intervenção didática foi avaliada mediante o diário de bordo da professora pesquisadora. Os resultados obtidos permitiram constatar que a realização de projetos ambientais é uma prática indicada para tornar o ensino de Ciências mais atrativo, fazendo com que os alunos ampliem seus conhecimentos e se tornem mais reflexivos sobre seu papel na sociedade e comunidade em que vivem.

Palavras-chave: atividades lúdicas; anos iniciais; ensino de ciências.

\section{Abstract}

The current text describe a study developed in a didactic interventation way, carried out in a primary grade fifth class on Science discipline within the Educational Environmental thematic. The central issue was to verify what extend a didactic intervention, shaped through ludic activities, can encourage the students to reflect upon the causes, consequences and possible solutions to environmental problems of their community. The data to elaborate the didactic sequence were obtained through a initial questionnaire which aimed to identify the main environmental problems faced by students in their community. The relevance of this pedagogical intervention was evaluated through teacher-researcher logbook. The results achieved allowed to identify that environment projects implementation is a suitable experience to make the Science teaching more attractive, providing students extend their knowledge and become more reflective about their role in society and community in which they live.

Keywords: play activities; early years; science teaching.

\footnotetext{
${ }^{1}$ Universidade de Passo Fundo | carinekleinbio@gmail.com

${ }^{2}$ Universidade de Passo Fundo | alinelocatelli@upf.br

${ }^{3}$ Universidade de Passo Fundo | alana@upf.br
} 


\section{Introdução}

Vivemos num mundo em que a produção e consumo em larga escala determinam as condições do ambiente, o que torna cada vez mais urgente uma mudança na forma de concebê-lo. No Brasil, o impacto ambiental, sobretudo nos grandes centros urbanos, é objeto de preocupações crescentes dos gestores públicos. De acordo com pesquisas do IBGE, os impactos que mais preocupam são os problemas com os recursos hídricos, a contaminação do solo e a poluição do ar. No caso da água e do solo, o agravante principal está relacionado à falta de saneamento e ao cuidado com a qualidade dos recursos, principalmente no meio rural, onde não há controle específico e a presença de resíduos de materiais orgânicos e inorgânicos, de origem animal ou humana, constitui o principal poluidor (WENTZ; NISHIJMA, 2011). Brabo et al. (2018, p. 107) mencionam que:
A preocupação com a preservação do meio ambiente não é recente. Muitos povos ao longo da História da Humanidade cultivaram práticas que atualmente poderiam ser rotuladas como sustentáveis. No entanto, a chamada Educação Ambiental é uma prática relativamente recente, cunhada no século XX, produto de reivindicações de grupos atingidos pelos males da exploração inconsequente de recursos naturais e poluição do ambiente.

A poluição desses recursos é originária, em grande parte, de ações antrópicas inconsequentes, enraizadas no consumismo exacerbado e na dependência de produtos industrializados aliados ao crescimento populacional desenfreado. A atividade humana gera impactos ambientais que repercutem nos meios físicos, biológicos e socioeconômicos afetando os recursos naturais e a saúde humana.

Diante da atual situação ambiental do planeta, é necessária maior sensibilização, reflexão e tomadas de decisões dos seres humanos, para reduzir e prevenir os constantes danos causados pela ação humana ao ambiente. Um dos principais espaços que pode tratar desse assunto é a escola, pois esta é um local de aprendizagem em que os sujeitos têm acesso e constroem o conhecimento, estando todos os dias em contato com situações que podem ser utilizadas para se trabalhar a Educação Ambiental (EA).

Considerando que a escola é, depois da família, o espaço mais significativo de experiências para a criança e a abordagem da EA torna-se essencial aos anos iniciais da escolarização, o presente texto dedica-se a apresentar os resultados de uma pesquisa realizada durante a aplicação de uma proposta didática que envolveu a abordagem de EA a partir de atividades lúdicas. Desse modo, buscou-se responder ao seguinte questionamento: em que medida uma intervenção didática estruturada por meio de atividades lúdicas pode estimular os educandos a refletir sobre as causas, consequências e possíveis soluções aos problemas ambientais de sua comunidade?

A partir desse questionamento, define-se como objetivo do estudo investigar a pertinência da proposta didática em termos de sua contribuição para a EA dos jovens. Para responder à questão do estudo, estrutura-se o texto de forma a apresentar inicialmente uma reflexão sobre a EA e o papel da escola; em seguida, descrevem-se a intervenção didática implementada e a pesquisa aplicada, explanando-se os resultados atingidos; por fim, apresentam-se as considerações finais. 


\section{A Educação Ambiental}

Desde o surgimento do homem na terra, o meio ambiente vem sendo alterado. A partir da Revolução Industrial, essas alterações tornaram-se mais evidentes e devastadoras causando graves efeitos ao meio ambiente. Embora a temática da questão ambiental seja algo constante e crescente há anos, é inegável que estamos mergulhados em uma crise ambiental. Por sua vez, é notável que tal crise possui origem sistêmica, uma vez que, na esfera mundial globalizada, tudo se interliga. No meio ambiente, não poderia ser diferente.

É urgente, portanto, a necessidade de um pensamento ecológico e de novas alternativas em todas as esferas da sociedade. A maneira como o ser humano se relaciona com a natureza e, consequentemente, consigo mesmo, exige mudança, mas ela precisa acontecer, a princípio, na forma como o ser humano se vê e percebe o mundo. Dessa forma, a EA surge como um instrumento transformador e aponta alternativas de minimizar os impactos dessa crise ambiental que vivenciamos.

Nesse contexto, aborda-se o surgimento do termo EA em 1965, na Conferência de Educação da Universidade de Keele, Inglaterra (EFFTING, 2007). No entanto, segundo Dias (2004), apenas em 1972, na Conferência de Estocolmo, a EA tornou-se campo de ação pedagógica, tendo relevância internacional. O ponto culminante ocorreu em 1977, em Tbilisi, na antiga URSS, onde se estabeleceu o quanto ela é essencial para a educação global. Em 1997, o Ministério da Educação elaborou uma nova proposta curricular, denominada Parâmetros Curriculares Nacionais (PCNs), para os quais o meio ambiente passa a ser um tema transversal nos currículos básicos do ensino fundamental.

Entretanto, em abril de 1999, com a Lei n. 9795/99, reconhece-se a importância da EA. Segundo essa lei, a EA tem de ser trabalhada dentro e fora da escola, mas não deve ser uma disciplina, porque perde seu caráter interdisciplinar. Deve estar presente no cotidiano escolar, "diluída" em todos os componentes, o que garante sua transversalidade. É importante ressaltar que o Brasil é o único país da América Latina que tem uma política nacional específica para EA (MEDEIROS; RIBEIRO; FERREIRA, 2011). Assim, de acordo com as Diretrizes Curriculares Nacionais para a EA, Art. $2^{\circ}$ :
A Educação Ambiental é uma dimensão da educação, é atividade intencional da prática social, que deve imprimir ao desenvolvimento individual um caráter social em sua relação com a natureza e com os outros seres humanos, visando potencializar essa atividade humana com a finalidade de torná-la plena de prática social e de ética ambiental. (BRASIL, 2012).

Segundo a Lei Federal n. 9.795, sancionada em 27 de abril de 1999, todos têm direito à EA como um "[...] componente essencial e permanente da educação nacional, devendo estar presente em todos os níveis e modalidades do processo educativo, em caráter formal e não formal [...]" (Lei n. 9.795/99).

Pela gravidade da situação ambiental em todo o mundo, assim como no Brasil, já se tornou categórica a necessidade de implementá-la para as novas gerações, em idade de formação de valores e atitudes, como também para a população em geral (GUIMARÃES, 1995). Todas as recomendações, decisões e tratados internacionais a colocam em primeiro lugar, para conseguir criar e aplicar formas sustentáveis de interação sociedade-natureza. Uma das formas de se chegar a isso é através da sensibilização das crianças, pois estas serão, daqui a 10 ou 15 anos, a geração que tomará decisões no mundo. 
De acordo com Trevisol (2003), ao propor a EA, espera-se que ela seja capaz de levar os indivíduos a reverem suas concepções e seus hábitos, transformando-os em pessoas mais conscientes e que tenham uma relação mais harmoniosa e sustentável com o meio onde estão inseridas. Ainda, segundo o autor:
A EA não é um tema qualquer que pode ser adiado ou relegado a segundo plano. Trata-se de uma necessidade histórica latente e inadiável, cuja emergência decorre da profunda crise socioambiental que envolve nossa época. Educar para a sustentabilidade tornou-se um imperativo, sobretudo porque as relações entre sociedade e natureza agravaram-se, produzindo tensões ameaçadoras tanto para o homem quanto para a biosfera. (TREVISOL, 2003, p. 93).

Com isso, as questões ambientais precisam ser trabalhadas com toda a sociedade, sobremaneira nas escolas, pois as crianças bem informadas sobre o assunto serão pessoas adultas mais preocupadas com o ambiente, além de transmitirem os conhecimentos que obtiveram na escola para sua família e vizinhos.

Todavia, é necessário que os educadores, juntamente com seus alunos, construam o processo de desenvolvimento de um sujeito ecológico. De acordo com Carvalho (2008), o sujeito ecológico é aquele com capacidade e sensibilidade para identificar e compreender os problemas ambientais, mobilizando-se e comprometendo-se com as decisões relacionadas ao ambiente equilibrado. A escola pode ser o espaço de análise e de descoberta de novas possibilidades de vida; por intermédio de atividades específicas, o professor leva o estudante a perceber o mundo complexo em que vive. É o local onde as crianças devem ser orientadas a ter uma postura crítica e consciente diante da vida e realidade, para, então, assumirem novas responsabilidades.

Uma boa ferramenta para se trabalhar a EA é desenvolver atividades educativas lúdicas, em que as crianças, juntamente com os professores, obtenham melhor interpretação dos conteúdos, proporcionar-lhes condições de expressarem o que pensam e acreditam, através de brincadeiras, desafios e soluções de problemas. Isso permite a percepção dos conhecimentos que os alunos já têm (SEGURA, 2001).

Não é nenhuma novidade que o emprego da ludicidade nas escolas se tornou uma ferramenta alternativa para o processo de ensino-aprendizagem, auxiliando na construção do conhecimento científico em geral. Viera et al. (2018) apresentam que a atividade lúdica mostra-se eficaz no processo de ensino-aprendizagem e na promoção da reflexão e ações acerca da EA.

Contudo, é evidente que a EA, por si, não resolve os complexos problemas ambientais planetários, mas pode influenciar decisivamente para minimizá-los, especialmente quando se preocupa com a formação de cidadãos conscientes do impacto de suas ações na natureza. É por isso que a relação EA e escola é tão importante, uma vez que é possível utilizar esse espaço para promover atividades diferenciadas e dinâmicas que envolvam, além dos alunos, a comunidade escolar. Dessa forma, pode-se propor que todos busquem alternativas para minimizá-los e, talvez, solucioná-los. Consoante Reigota (2009), ter consciência e conhecimento da problemática global e atuar na comunidade pode promover uma mudança na vida cotidiana que, se não é de resultados imediatos, visíveis, em longo prazo, trará mudanças significativas na relação ser humano e meio ambiente. 


\section{A intervenção didática}

Na busca por propor alternativas didáticas que possam contribuir com a presença de uma EA nas escolas, este estudo desenvolveu uma proposta didática que foi aplicada em uma escola pública municipal, localizada no Distrito de Santa Rosa, interior da cidade de Palmeira das Missões, RS. O público-alvo dessa intervenção foram os dez alunos que integram $05^{\circ}$ ano do ensino fundamental.

A proposta foi estruturada com base nos problemas ambientais vivenciados pelos estudantes. Para isso, eles responderam a um questionário que buscou elencar quais os principais problemas ambientais presentes na comunidade/município de Palmeira das Missões. Essa ação tomou por referência o mencionado por Araújo e Puig (2007), ao destacarem a importância de se conhecer a realidade social em que a comunidade escolar se insere, bem como o ambiente natural e cultural de seu entorno para, então, tornar a educação para a cidadania efetiva. Ainda, é necessário ter claro que a relação entre a EA e a formação e exercício da cidadania deve ser crítica, ética, responsável e inovadora. Esse processo deve ser permanente e valorizar as diversas formas de conhecimento, formando cidadãos com consciência local e planetária.

Como mencionado, a proposta didática começou a ser estruturada a partir da sondagem dos principais problemas ambientais presentes na comunidade/município de Palmeira das Missões, ou seja, levantaram-se os problemas ambientais vivenciados pelos estudantes no seu dia a dia. As respostas ao questionário inicial estão ilustradas no Gráfico 1.

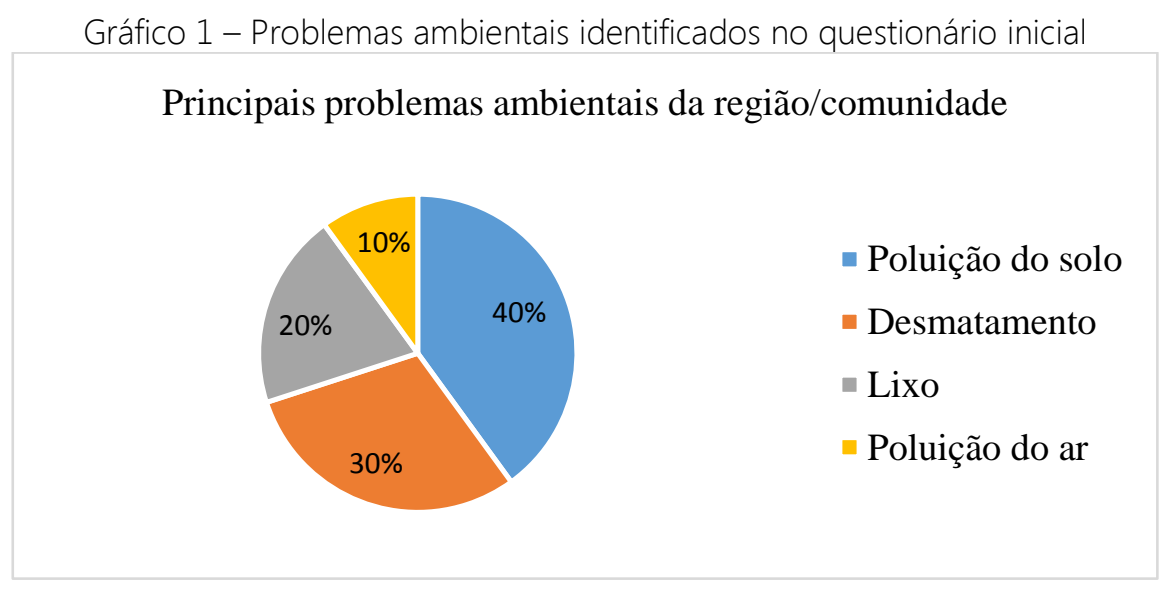

A proposta consistiu em identificar três problemas segundo o entendimento dos estudantes e a partir deles organizar atividades lúdicas que possibilitassem tratar os temas elencados. Esses temas foram trabalhados em encontros que estão descritos na sequência. Antes, porém, apresenta-se o Quadro 1, que identifica a atividade desenvolvida e o tempo de duração de cada uma delas.

No primeiro encontro, foi aplicado o questionário mencionado e discutidas, com os alunos, as respostas obtidas. No segundo e terceiro encontros, revisou-se o conceito de poluição do solo, os principais tipos de poluição, as principais consequências e, em seguida, 
discutiram-se os problemas locais. Após, foi realizada a brincadeira "Em busca do Tesouro" ${ }^{\prime 4}$. Essa atividade foi executada ao ar livre e contou com a delimitação do espaço com fitas, em que se distribuíram garrafas pet, latinhas, embalagens de plástico, papel, entre outros, formando uma trilha. Os alunos organizaram-se em duplas e receberam uma sacola para armazenagem dos materiais, tendo 30 minutos para procura desses materiais. Ao final, foi feita a contagem dos objetos encontrados e a dupla que teve o maior número foi decretada vencedora.

Quadro 1 - Encontros e atividades desenvolvidas.

\begin{tabular}{c|l|c}
\hline Encontros & \multicolumn{1}{|c|}{ Atividades } & Tempo \\
\hline $1^{\circ}$ & $\begin{array}{l}\text { Aplicação do questionário inicial de sondagem de problemas } \\
\text { ambientais presentes na comunidade. }\end{array}$ & $1 \mathrm{~h}$ \\
\hline $2^{\circ}$ e $3^{\circ}$ & $\begin{array}{l}\text { Atividades lúdicas sobre poluição dos solos: "Em busca do } \\
\text { Tesouro" e "Poluição do Solo: Causa X Consequência". }\end{array}$ & $2 \mathrm{~h}$ \\
\hline $4^{\circ}$ e $5^{\circ}$ & $\begin{array}{l}\text { Atividades lúdicas sobre desmatamento: "Dinâmica das Frases" e } \\
\text { "Tempo X Lenhador". }\end{array}$ & $2 \mathrm{~h}$ \\
\hline $6^{\circ}$ e $7^{\circ}$ & $\begin{array}{l}\text { Atividades lúdicas sobre lixo: "Lixo: precisamos cooperar" e } \\
\text { "Repolho Quente da Reciclagem". }\end{array}$ & $2 \mathrm{~h}$ \\
\hline $8^{\circ}$ & Questionário final. & $1 \mathrm{~h}$ \\
\hline
\end{tabular}

A segunda atividade lúdica dessa temática foi denominada "Poluição do Solo: Causa x Consequência" ${ }^{4}$, sendo realizada em sala de aula. Para isso, a professora confeccionou antecipadamente os cartões e caixas utilizados. A turma foi organizada em dois grupos de cinco alunos e cada grupo recebeu dez cartões. Eles se reuniram e discutiram sobre as causas e consequências da poluição do solo, selecionaram cinco causas e cinco consequências que foram escritas nos cartões (causas mencionadas: indústrias, uso de agrotóxicos, falta de coleta de lixo, falta de saneamento básico, lixo em áreas indevidas, enterro de resíduos tóxicos, atividades de mineração, etc. Consequências identificadas: solo infértil para plantio, contaminação de rios, contaminação de lençol freático, desequilíbrio do ecossistema, extinção de plantas e animais, deslizamento de terras, doenças aos seres humanos, etc.). Em seguida, os grupos organizaram-se, individualmente, em duas filas indianas. Quando recebiam o sinal, simultaneamente, pegavam uma das fichas, liam e determinavam se o que estava ali era causa ou consequência da poluição do solo. Então, depositavam-na na caixa correspondente. Ganhou o grupo que terminou a fila primeiro. A Figura 1 ilustra o momento da atividade.

No $4^{\circ}$ e $5^{\circ}$ encontros, uma breve introdução sobre as causas e consequências do desmatamento e os problemas enfrentados pelo município. Em seguida, realizou-se a brincadeira denominada "Dinâmica das Frases". Para isso, a professora organizou previamente frases relacionadas à temática do desmatamento: "Uma maneira de ajudar a cuidar do nosso planeta é não derrubar árvores"; A derrubada de florestas provoca graves prejuizos à fauna e à flora de uma região"; "Quem desmata destrói a si e aos demais seres vivos". As palavras foram escritas em uma folha de modo que cada um dos dez alunos recebesse uma delas. A turma foi organizada em um grande grupo e cada estudante

\footnotetext{
${ }^{4}$ Atividade adaptada do material "Dinâmicas e Jogos para Educação Ambiental" do Seminário de Educação Ambiental Parque Nacional do Iguaçu. Disponível em: <https://goo.gl/ebyKu9>.
} 
recebeu uma folha. Depois disso, os alunos tiveram cinco minutos para organizar uma frase, que, na sequência, foi verificada pela professora e, quando correta, desencadeava uma discussão e, assim, sucessivamente até completar cinco rodadas.

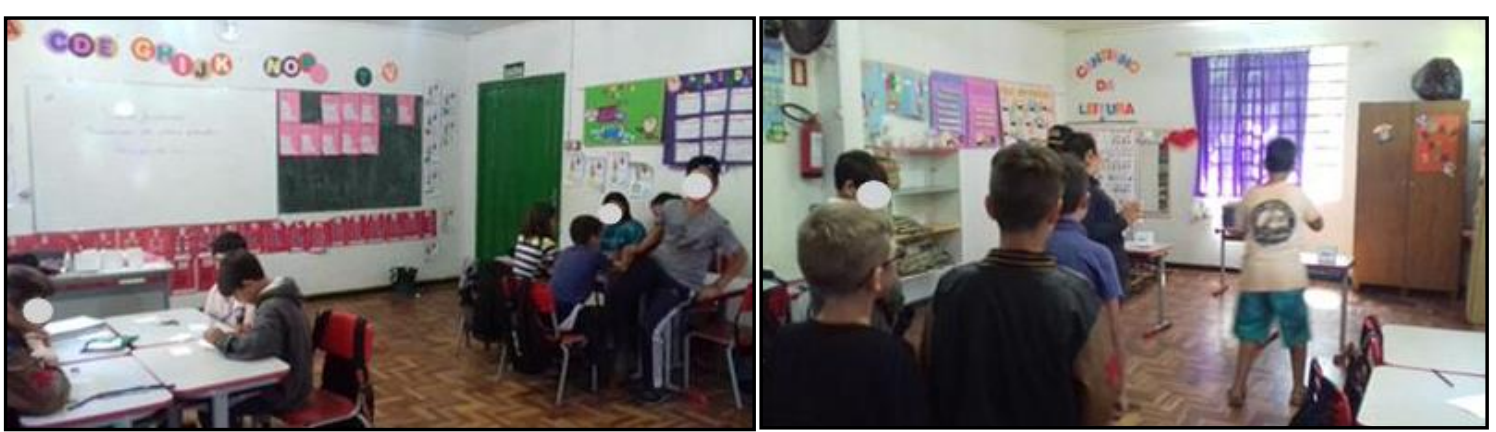

Figura 1 - Alunos trabalhando com os cartões (à direita); alunos em fila para depositar os cartões nas caixas corretas (à esquerda)

A atividade lúdica realizada sobre a temática desmatamento intitulou-se "Tempo $x$ Lenhador" . Primeiramente, ocorreu a explicação sobre as regras da brincadeira, em que o "lenhador" se empenhava para cortar o máximo de árvores possíveis, enquanto o "tempo" deve fazer de tudo para recuperar a área desmatada. A ação de cortar uma árvore pelo "lenhador" estava representada por colocar a mão no ombro do colega que, por sua vez, deveria deitar-se no chão, passando a representar a grama. Para que a grama cresça, é necessária a ajuda do "tempo" que, tocando nas "gramas", fará com que elas cresçam e tomem a forma de arbusto (posição agachada). Se o "tempo" tocar novamente nos alunos que representam arbustos, estes finalmente se levantam e voltam a ser árvores. Porém, caso o "lenhador" tocar em um arbusto, este voltará a ser grama. Na atividade, posicionaram-se os alunos que representaram o "tempo" e o "lenhador" em lados opostos. Após a largada, a dinâmica aconteceu com o "lenhador" e o "tempo" atuando na floresta por aproximadamente cinco minutos. Após, parou-se a brincadeira e, com os alunos, contou-se quantas árvores e arbustos existem na área. Ao final, foi enfatizado que os impactos do desmatamento são mais rápidos que a recuperação da natureza. Dessa forma, cabe aos seres humanos refletirem constantemente sobre suas ações e os impactos que seu modo de interagir causa ao local onde habitam.

No $7^{\circ}$ e $8^{\circ}$ encontros, foi feita uma proposta de discussão sobre a responsabilidade de cada cidadão quanto ao problema do lixo no mundo, no nosso país e na nossa cidade. Depois, revisaram-se as causas e consequências do descarte incorreto dos resíduos, o tempo de decomposição de cada material, a importância da coleta seletiva e da separação correta dos resíduos, incluindo a construção de composteiras.

Na sequência, a professora coordenou a brincadeira "Lixo: precisamos cooperar", que foi realizada na sala de aula da seguinte maneira: a turma formou um grande círculo e os alunos ficaram com as mãos dadas e virados para o centro. A professora distribuiu os materiais previamente organizados no meio da roda e deixou as lixeiras nas extremidades. Os alunos, sem soltar as mãos uns dos outros, deveriam colocar todo o lixo distribuído nas 
lixeiras corretas. A professora contextualizou a atividade com o fato de encarar o problema do lixo e buscar uma "saída para o desafio".

A segunda atividade lúdica foi denominada "Repolho Quente da Reciclagem" ${ }^{5}$, que correspondeu à tradicional brincadeira "batata-quente". Para isso, a docente produziu em casa, com rascunhos de folha de ofício (visando sempre ao reaproveitamento), o repolho. Este foi formado por cerca de 20 folhas amassadas, envoltas entre si com questões sobre os problemas com o lixo e a importância da coleta seletiva (Por que o lixo abandonado causa doenças? Quais materiais podem ser reciclados? O que significa reciclar? Qual produto é obtido na compostagem? Diferencie aterro sanitário de lixões? Diga três formas de poluição do meio ambiente. Defina poluição). Os alunos organizaram-se em círculo; um deles ficou de olhos vendados no centro da roda e era o responsável por parar a circulação do repolho entre os demais integrantes da atividade. Quando se apontasse o comando, a pessoa que estivesse com o repolho deveria "descascá-lo", ler a pergunta e respondê-la. Se a resposta estivesse correta, a brincadeira continuava; caso contrário, o aluno deveria trocar de lugar com o colega que estava no centro do círculo.

A Figura 2 ilustra a atividade realizada com os estudantes.

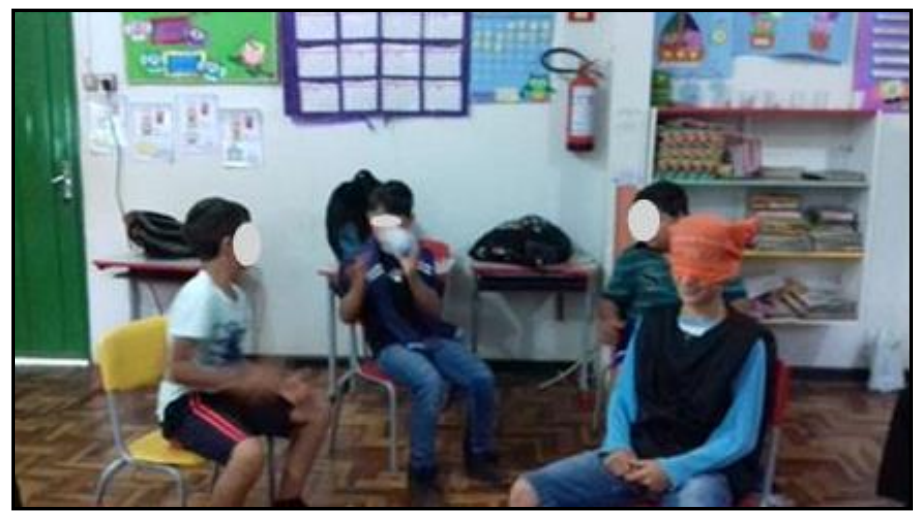

Figura 2 - Alunos brincando Repolho Quente da Reciclagem

\section{A pesquisa}

A pesquisa desenvolvida no estudo é de natureza qualitativa. De acordo com Minayo (2002), caracteriza-se por trabalhar com o universo dos significados, dos motivos, das aspirações, das crenças, dos valores e das atitudes. Triviños (1994) defende que a pesquisa qualitativa trabalha os dados de forma a buscar seus significados tendo como base a percepção do fenômeno em seu contexto. A descrição qualitativa procura captar não só a aparência do fenômeno, mas também suas essências, visando explicar sua origem, relações e mudanças e tentando intuir possíveis consequências.

Como instrumento para coleta de dados, utilizaram-se o questionário inicial e o diário de bordo. O questionário inicial foi utilizado para elaboração da intervenção didática e sua finalidade foi diagnosticar os problemas ambientais, sobretudo os mais evidentes na

\footnotetext{
${ }^{5}$ Atividade retirada do material "Dinâmicas e Jogos para Educação Ambiental" do Seminário de Educação Ambiental Parque Nacional do Iguaçu. Disponível em: <https://goo.gl/ebyKu9>.
} 
comunidade local e na percepção dos estudantes participantes do estudo. O diário de bordo foi utilizado pela professora pesquisadora para registrar as reflexões a respeito do trabalho realizado, bem como os aspectos positivos e negativos do material produzido até as reações dos educandos durante a execução das atividades. Segundo Zabalza (1994), o diário de bordo permite ao professor registrar, analisar e compreender como determinado instrumento funciona. Ainda permite avaliar as aulas e destacar os pontos positivos e negativos, possibilitando uma reflexão acerca da metodologia utilizada e, consequentemente, uma reestruturação e melhora na execução das aulas.

\section{Análise e discussão dos resultados}

Para discutir os resultados obtidos, utilizando o diário de bordo como instrumento para coleta de dados, procedeu-se à estruturação desses dados em categorias que representam agrupamentos. Tais categorias tomam por referência os temas tratados na intervenção didática, quais sejam: "poluição do solo", "desmatamento" e "lixo".

A discussão que segue nas categorias mencionadas apoia-se nos registros efetuados no diário de bordo pela professora pesquisadora - uma das autoras deste artigo. Os registros realizados buscaram capturar observações e fatos mais relevantes constatados pela pesquisadora, durante a realização dos encontros e serviram para avaliar a intervenção didática. Nas discussões que seguem, os registros extraídos diretamente do diário estão destacados em itálico, corrigidos os vícios de linguagem e identificados de forma alfanumérica (E1, E2, E3...) quando se referem a registros de manifestações dos estudantes.

\section{a) As atividades lúdicas sobre "poluição dos solos"}

As atividades lúdicas foram desenvolvidas em dois encontros de uma hora/aula cada. Inicialmente, discutiram-se as questões ambientais relacionadas à temática "Solo". Os alunos foram instigados a refletir acerca dos problemas ambientais relacionados ao solo, que estavam próximos a eles, quais eram os tipos de poluição, as consequências que esse problema pode ocasionar aos seres vivos e ao planeta como um todo.

Muitos estudantes se manifestaram expondo opiniões parecidas. Para eles, o maior problema na região em que vivem está relacionado ao "uso de venenos nas lavouras" (E1) e ao "descarte incorreto das embalagens" (E2). Sabe-se que a agricultura requer uma grande quantidade de insumos, como fertilizantes, agrotóxicos e reguladores de crescimento para que se desenvolva de forma eficaz e rentável. Todavia, uma parcela dos agroquímicos aplicados nas culturas acaba sendo incorporada ao solo, seja na aplicação, por não atingir o alvo, seja através da infiltração, dissolvidos na solução do solo, seja, ainda, perdida para a atmosfera por volatilização (CHAIM et al., 1999a, 1999b).

Contudo, conforme Filizola et al. (2002), entender o comportamento dos agrotóxicos na terra e utilizá-los da maneira mais correta possível pode minimizar seus efeitos nocivos sobre o meio ambiente. Para isso, é necessário conhecimento do solo, incluindo a dinâmica da água na área e as características e o comportamento de cada princípio ativo. Essas informações podem ser obtidas pelos agricultores com a Empresa de Assistência Técnica e Extensão Rural do Governo do Distrito Federal (Emater), que tem como função orientar e dar assistência técnica cumprindo sua missão de promover o desenvolvimento rural sustentável. 
Nessa discussão, alguns educandos também ressaltaram que a falta de coleta de lixo na região onde moram ocasiona o acúmulo desses detritos no solo, que acabam sendo carregados pelas chuvas para córregos e riachos, ocasionando poluição das águas. Nesse momento, foi possível trabalhar um pouco sobre outros dois problemas ambientais: o descarte incorreto dos resíduos e a poluição da água - ambos com preocupação global.

Posteriormente, os educandos foram desafiados a conceituar "Poluição do Solo". A atividade mostrou um resultado preocupante, pois não houve uma definição clara do referido problema. As respostas estavam todas relacionadas às causas da poluição, conforme registrado no diário de bordo pela professora pesquisadora:

Ao serem questionados sobre o conceito de poluição do solo, pude perceber que poucos alunos se manifestaram, estes apresentaram uma ideia confusa, utilizando a causa da poluição do solo para conceituá-la. Para eles, poluição do solo resume-se a jogar lixo no chão (DIÁRIO DE BORDO, registro do dia 28/11/2017).

Diante desse diagnóstico, foi necessário organizar e definir de forma simples o conceito de poluição do solo, suas causas e consequências. Para isso, a própria pesquisadora organizou e utilizou o seguinte esquema (Figura 3).

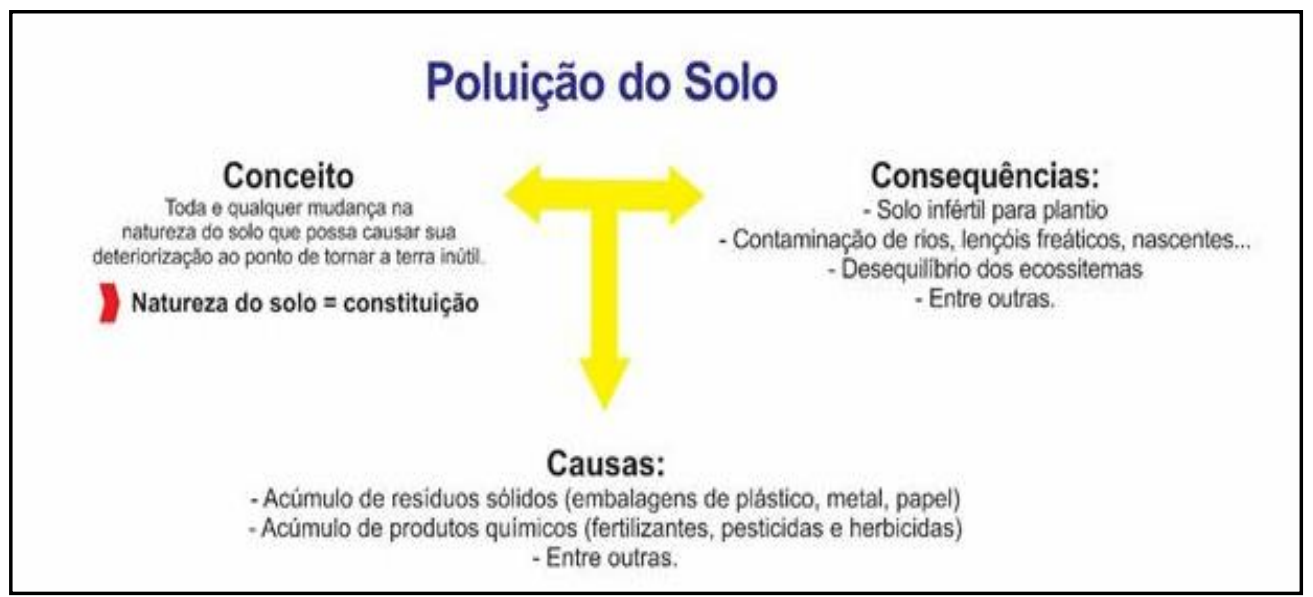

Figura 3 - Esquema utilizado pela professora para auxiliar na compreensão do tema "Poluição do solo"

Em seguida, realizaram-se as atividades lúdicas sobre a temática abordada Em busca do Tesouro" e "Poluição do Solo: Causas x Consequências", as quais são relatas na sequência.

Para a atividade "Em busca do Tesouro" relatada na seção anterior, os registros da pesquisadora apontaram que, durante a realização da brincadeira, os estudantes participaram ativamente, mostrando um envolvimento e prazer em aprender, o que é característico de atividades lúdicas. Juy (2004) defende que jogos e brincadeiras são excelentes oportunidades de mediação entre o prazer e o conhecimento historicamente constituído, já que o lúdico é eminentemente cultural. A prática de atividades lúdicas em sala de aula é uma forma gostosa de trabalhar os conteúdos, pois a criança sente prazer e se diverte com as atividades agregando cada vez mais conhecimentos.

Isso pode ser constatado pelo registro no diário de algumas falas dos estudantes: "Foi muito massa, professora! Podemos fazer mais vezes" (E9); "Seria legal se todos os conteúdos pudessem ser estudados com brincadeiras ou jogos." (E5). Outra anotação 
importante pode ser verificada na manifestação do E1: "Vou parar de jogar lixo no chão, dá muito trabalho juntar tudo e ainda polui o meio ambiente".

$\mathrm{Na}$ atividade sobre a "Poluição do Solo: Causas x Consequências", observou-se que algumas definições ainda estavam confusas para alguns alunos, havendo dificuldade na hora de determinar, por exemplo, aterros sanitários como causas da poluição do solo e contaminação do lençol freático como consequência desse tipo de poluição. Essa percepção foi registrada no diário de bordo, ao final da atividade, assim como outras considerações em relação à execução da brincadeira: "Ao perceber que os educandos ainda apresentavam dúvidas sobre o assunto, busquei esclarecê-las com novas explicações, exemplos e esquemas na lousa" (DIÁRIO DE BORDO, registro do dia 30/11/2017).

\section{b) As atividades lúdicas sobre "desmatamento"}

A atividade sobre desmatamento buscou levar os alunos a refletir sobre como eram as terras que seus pais utilizam antes de virarem lavouras de soja, milho, trigo e erva, entre outros. Ao serem questionados sobre isso, os alunos revelaram ter conhecimento a respeito, conforme registro do diário de bordo da professora: "com certeza, devia ser mata nativa e foi derrubada para plantação" (E7); "acho que já tinha lavoura porque essa é uma prática bem antiga" (E1); "era mato e foi derrubado" (E2). A partir das respostas, construiu-se o conceito de desmatamento, sendo expostas suas causas e consequências.

Sabe-se que o desmatamento ilegal ainda é a maior fonte de poluição. Seus impactos incluem a extinção de espécies animais e vegetais, acarretando perda de biodiversidade, interferência no ciclo da água e liberação de gases que contribuem para o aquecimento global. O Brasil sofre com esse problema, principalmente quando se fala na Floresta Amazônica, uma das grandes vítimas do desmatamento. Sobre isso, Chomitz (2007) mostra que uma das alternativas para tentar conter os desmatamentos seria a melhoria da governança florestal, buscando equilibrar interesses entre grupos, melhorar os monitoramentos públicos, regular os direitos de propriedade e regulamentar a exploração de florestas públicas e privadas.

Durante o diálogo com os estudantes, foi possível perceber que eles têm uma percepção bem significativa sobre essa temática. Apesar da pouca idade e da imaturidade, eles revelaram conhecimento empírico sobre os assuntos que envolvem seu cotidiano (lavouras, áreas de mata que podem ou não ser cortadas, madeiras utilizadas para comercialização...). Tal conhecimento vem, segundo relato, dos diálogos com pais, avós e tios. O registro do diário de bordo da professora evidencia essa constatação: "[...] muitos dos alunos revelaram que conversam com seus familiares sobre isso e, embora o desmatamento tenha sido uma alternativa econômica das familias, ele também tem consciência sobre o impacto disso no meio ambiente" (DIÁRIO DE BORDO, registro do dia 05/12/2017).

Segundo Freire e Horton (2005), o educador deve respeitar o conhecimento que o aluno traz para a escola, haja vista que ele é um sujeito social e histórico; logo, compreender que formar é muito mais do que puramente treinar o educando no desempenho de destrezas. Ainda, o autor determina que a educação deve promover a autoconfiança e toda ação educativa deve ser um ato contínuo de recriação e de ressignificação de significados enquanto condição de possibilidade para uma educação conscientizadora e libertadora. 
Dando continuidade às atividades, realizou-se a "Dinâmica das Frases", cujo objetivo estava em elaborar frases relacionadas ao tema "desmatamento", sendo as palavras definidas previamente pela professora. Essa brincadeira permitiu que os alunos pensassem com calma e interagissem com todos os colegas. Acredita-se que, por esse motivo, alguns estudantes se manifestaram negativamente em relação à atividade, manifestando expressões, como: "não gostei disso, muito chato ter que ficar pensando..." (E4); "ah professora, vamos fazer outra coisa" (E10). Apesar dos comentários, sabe-se que a construção da autonomia dos educandos é necessária; portanto, o professor deve ajudá-lo a pensar, a ser curioso, a aceitar o novo, a arriscar sem ter medo de errar.

Freire (2002) afirma a necessidade de os educadores criarem condições para a construção do conhecimento pelos educandos como parte de um processo em que ambos não se reduzam à condição de objeto um do outro, pois ensinar não é transferir conhecimento, mas criar as possibilidades para sua própria produção. Isso só é possível porque somos seres humanos e, dessa maneira, temos consciência de que somos inacabados. É essa consciência que nos instiga a pesquisar, perceber criticamente e modificar o que está condicionado, mas não determinado, passando a sermos sujeitos, e não apenas objetos da nossa história.

O encerramento desse encontro ocorreu com a atividade lúdica "Tempo x Lenhador", que foi realizada na quadra de esportes da escola e possibilitou que os alunos corressem e se divertissem muito. De acordo com as anotações da pesquisadora em seu diário de bordo, essa foi a brincadeira que os alunos mais demonstraram satisfação e empolgação. De acordo com seus registros, os alunos conseguiram perceber de forma mais clara que o tempo para desmatar é muito mais curto do que o tempo que a natureza leva para se regenerar.

\section{c) As atividades lúdicas sobre "lixo"}

Esses dois encontros foram organizados para tratar da temática "lixo". Atualmente, esses são assuntos de grande relevância para o município, pois, há menos de um ano, foi estabelecida pelos órgãos administrativos a coleta seletiva do lixo em toda a zona urbana do município. Todavia, na zona rural, nem todos os moradores foram contemplados pelo recolhimento dos resíduos, seja a coleta comum, seja a seletiva. Dos dez participantes do estudo, apenas um, por morar na zona urbana, mencionou possuir coleta seletiva em sua residência. Os demais relataram buscar diferentes alternativas para descartar seus resíduos. Entre as opções elencadas, estava o de queimá-los ou enterrá-los. Esses são hábitos antigos e ainda muito utilizados nos dias de hoje por grande parte da população.

Por essa razão, a docente expôs aos estudantes a Lei n. 9605/1998, que define a queima de lixo como crime e a Política Nacional de Resíduos Sólidos (Lei n. 12.305/2010), que enfatiza a proibição da queima a céu aberto de resíduos sólidos ou de forma não licenciada. Além disso, a referida lei define a correta destinação: orgânicos devem ser encaminhados à compostagem; rejeitos, aos aterros licenciados; recicláveis, à indústria de transformação; resíduos perigosos, aos aterros industriais ou devolvidos ao fabricante.

Como reflexão oportunizada por essa discussão e pela atividade desenvolvida, os alunos manifestaram suas opiniões a respeito da responsabilidade de cada cidadão sobre o problema do lixo no planeta. No diário de bordo da professora, esse momento foi registrado com relato de fala dos alunos: "o problema do lixo começa em casa quando não se separam corretamente os resíduos" (E2); "o problema está na falta de consciência de 
cada pessoa, precisamos começar pela própria sala de aula" (E3); "precisamos consumir coisas com menos embalagens e evitar jogar tanta coisa na natureza" (E6). Nesse momento, corroborando com a fala de um dos alunos, a professora ressaltou a importância do nosso papel de cidadãos na geração de mudanças que tragam benefícios ao meio ambiente.

Na sequência, realizou-se, em sala de aula, a atividade lúdica "Lixo: precisamos cooperar", cujo objetivo era separar corretamente os resíduos. Essa atividade foi conturbada, devido ao espaço pequeno e ao fato de os alunos estarem de mãos dadas e terem de trabalhar de forma cooperativa. Tal situação permitiu analisar a interação alunoaluno que não é satisfatória na turma como um todo, pois os estudantes trabalham melhor de acordo com as afinidades pré-estabelecidas; quando há uma quebra desse padrão, apresentam certa resistência.

Ao trabalharem em grupos não estabelecidos por afinidade, os alunos apresentaram certa resistência e dificultaram a concretização das atividades. Isso é algo que me preocupa, pois como educadora sei que o trabalho cooperativo pode trazer resultados relevantes para o aprendizado (DIÁRIO DE BORDO, registro do dia 07/12/2017).

Em seguida, foram explanadas as causas e consequências do descarte incorreto dos resíduos e estabeleceu-se uma relação entre o tempo de decomposição de alguns materiais no ambiente. Posteriormente, foi realizada a atividade lúdica denominada "Repolho Quente da Reciclagem". De acordo com os registros, os alunos se envolveram positivamente com a atividade, evidenciando a importância de proporcionar momentos como os realizados nesse estudo:
Hoje a aula foi muito produtiva, os alunos adoraram a brincadeira batata quente adaptada, não queriam sair para o intervalo para não interromper. Ainda, demonstraram ter entendido com facilidade os assuntos relacionados à temática desta aula respondendo com êxito às perguntas que surgiam durante a atividade e por manifestações como: "vou falar para o pai não queimar mais o lixo" (E6); "precisamos fazer a nossa parte, começando pela separação dos resíduos" (E9). (DIÁRIO DE BORDO, registro do dia 07/12/2017).

Continuando a abordagem sobre a temática do lixo e da coleta seletiva, a pesquisadora exemplificou como se constrói uma composteira e ficou surpresa com o grande conhecimento dos alunos a respeito dessa prática. Conclui-se que isso se deve ao fato de eles realizarem o reaproveitamento dos restos de alimentos para produção de adubo (composteira) ou para a alimentação dos animais. Nessa discussão, foram apresentados aos alunos aspectos relacionados à separação correta dos resíduos, os quais consultaram a cartilha para visualizar as tabelas e ilustrações sobre o assunto. Nessa cartilha, foram apresentados aspectos vinculados à questão social e à importância da conscientização dos sujeitos sobre seu papel na sociedade.

Nesse contexto, ficou saliente o papel da escola como responsável por auxiliar os alunos na busca por um processo de formação voltado à conscientização e à criticidade. Formar cidadãos críticos e preparados para enfrentar o mundo vivencial, com seus problemas e desafios, é tarefa das famílias e, também, das instituição de ensino, conforme destacado por Scheid (2018, p. 234). Para a autora, as instituições de ensino exercem forte influência na promoção do exercício para a cidadania. Em suas palavras, 
[...] cabe às instituiç̧ões educativas, o papel de contribuir para a alfabetização cientifica e tecnológica dos indivíduos tendo como fim possibilitar-Ihes o exercício pleno da cidadania. Essa cidadania relacionase com o desenvolvimento das habilidades e competências que possibilitam ao indivíduo a compreensão da realidade social, política, civil e cultural que o cerca. As instituições educativas, como centro de formação cidadã, devem ter a preocupação de possibilitar oportunidades para que o indivíduo, ali presente, desenvolva as capacidades de atuar ativamente na sociedade. Esta atuação se refere à maneira como ele se posiciona frente aos desafios e como elabora soluções para as questõesproblemas do meio em que vive.

O mencionado pela autora corrobora a perspectiva de que, em sala de aula, o professor pode trazer para discussão temas vinculados ao cotidiano do aluno e, com isso, permitir o debate e a reflexão acerca dos conhecimentos necessários à compreensão do mundo, sem, contudo, esquecer, a responsabilidade de permitir que os estudantes adquiram conhecimentos para avançar em seus estudos.

\section{Considerações finais}

O presente estudo buscou compreender em que medida uma intervenção didática estruturada por meio de atividades lúdicas pode estimular os educandos a refletir sobre as causas, consequências e possíveis soluções aos problemas ambientais de sua comunidade. A partir das premissas expressas no corpo da investigação, foi observado que a EA está muito presente no cotidiano dos alunos, os quais apresentam uma percepção desses eventos, pois conseguem discutir o assunto de forma clara e coerente.

A associação da ludicidade aos conhecimentos científicos discutidos na intervenção didática inferiu resultados interessantes e satisfatórios, pois tornou a discussão dessa temática mais prazerosa e significativa aos educandos. O lúdico pode trazer à aula um momento de felicidade, seja qual for a etapa da vida, acrescentando leveza à rotina escolar e fazendo com que o aluno registre, de forma mais significativa, os ensinamentos (ROLOFF, 2010).

Além disso, a pesquisa reafirma a importância da interação professor-aluno dentro da sala de aula para o sucesso no processo de ensino-aprendizagem, como indicado por Freire (2002), ao defender o diálogo como importante instrumento na constituição dos sujeitos. Desse modo, quanto mais o professor compreender a grandeza do diálogo como atitude necessária em sala de aula, maiores os resultados conquistados em relação aos alunos, pois estes se sentirão mais curiosos e determinados a modificar a realidade. É isso que a EA quer provocar nos cidadãos. 


\section{Referências}

ARAÚJO, U. F. de; PUIG, J. M. A construção social e psicológica dos valores. In: ARANTES, Valéria A. (Org.). Educação e Valores. São Paulo: Summus, 2007.

$B R A B O$, J. C. et al. Protocolo para coleta e análise de ideias e preocupações de professores sobre Educação Ambiental (PCA-EA). Revista Brasileira de Ensino de Ciência e Tecnologia, Ponta Grossa, v. 11, n. 2, p. 105-124, 2018.

BRASIL. Ministério da Educação e do Desporto, Lei n. 9.795 de 27 de abril de 1999. Dispõe sobre a educação ambiental, institui a Política Nacional de Educação Ambiental e dá outras providências. Diário Oficial da República Federativa do Brasil, Brasília, DF, n. 79, 28 abr. 1999.

BRASIL. Resolução n. 2, de 15 de junho de 2012. Estabelece as Diretrizes Curriculares Nacionais para a Educação Ambiental. Diário Oficial da União, Brasília, DF, n. 116, seção 1, p. 70, 18 jun. 2012.

CARVALHO, I. C. M. Educação ambiental: a formação do sujeito ecológico. São Paulo: Cortez, 2008.

CHAIM, A. et al. Método para monitorar perdas na aplicação de agrotóxicos na cultura do tomate. Pesquisa Agropecuária Brasileira. Brasília, DF, v. 34, n. 5, p. 741-747, 1999a.

CHAIM, A. et al. Validação de método para estudo de deposição de inseticidas biológicos em florestas. Jaguariúna: Embrapa Meio Ambiente, 1999b. (Embrapa Meio Ambiente, Boletim de Pesquisa, 4).

CHOMITZ, K. M. Em desacordo? Expansão Agrícola, Redução da Pobreza e Meio Ambiente nas Florestas Tropicais. Relatório do Banco Mundial, 2007. Disponível em:

<https://goo.gl/MMx6gN>. Acesso em: 16 mar. 2018.

DIAS, G. F. Educação ambiental: princípios e práticas. 9. ed. São Paulo: Gaia, 2004.

EFFTING, T. R. Educação Ambiental nas escolas públicas: realidade e desafios. 2007. Monografia (Especialização em Planejamento para o Desenvolvimento sustentável) Universidade Estadual do Oeste do Paraná, Marechal Cândido Rondon, 2007.

FILIZOLA, N. et al. Caracterização hidrológica da bacia Amazônica. In: RIVAS, A.; FREITAS, C. (Org.). Amazônia uma perspectiva interdisciplinar. Manaus: EDUA, 2002.

FREIRE, P. Pedagogia do oprimido. 34. ed. São Paulo: Paz e Terra, 2002.

FREIRE, P.; HORTON, M. O caminho se faz caminhando: conversas sobre educação e mudança social. 3. ed. Petrópolis, RJ: Vozes, 2005.

GUIMARÃES, M. A dimensão ambiental na educação. Campinas: Papirus, 1995.

JUY, A. F. Brincando também se aprende Português. 2004. Trabalho de Conclusão do Curso (Graduação em Letras) - FACINOR, Loanda, 2004. 
MEDEIROS, M. C. S.; RIBEIRO, M. da C. M.; FERREIRA, Catyelle Maria de Arruda. Meio ambiente e educação ambiental nas escolas públicas. Âmbito Jurídico, Rio Grande, n. 92, set. 2011. Disponível em: <https://bit.ly/2JKZrsJ >. Acesso em: 12 jan. 2018.

MINAYO, M. C. S. (Org.). Pesquisa social: teoria, método e criatividade. 21. ed. Petrópolis: Vozes, 2002.

REIGOTA, M. A. O que é educação ambiental. São Paulo: Brasiliense, 2009.

ROLOFF, E. M. A importância do lúdico em sala de aula. In: SEMANA DE LETRAS, 10, 2010, Porto Alegre. Anais... Porto Alegre: PUC, 2010. Disponível em: <https://goo.gl/xaX4rH>. Acesso em: 6 maio 2018.

SCHEID, N. M. J. História da Ciência na educação científica e tecnológica: contribuições e desafios. Revista Brasileira de Ensino de Ciências e Tecnologia, v. 11, n. 2, p. 233-248, 2018.

SEGURA, D. de S. B. Educação Ambiental na escola pública: da curiosidade ingênua à consciência crítica. São Paulo: Annablume: Fapesp, 2001.

TREVISOL, J. V. A educação em uma sociedade de risco: tarefas e desafios na construção da sustentabilidade. Joaçaba: Ed. da Unoesc, 2003.

TRIVIÑOS, A. N. S. Introdução à pesquisa em ciências sociais: a pesquisa qualitativa em educação. 4. ed. São Paulo: Atlas, 1994.

VIEIRA, Y. et al. "O óleo, nós e o planeta": peça de teatro para promover sensibilização e educação ambiental. Cataventos, v. 10, n. 1, p. 1-14, 2018.

WENTZ, F. M. A.; NISHIJIMA, T. A educação ambiental como meio de ação nas atividades agrícolas para preservação dos solos e da água nas comunidades rurais do Município de Santo Ângelo - RS. Revista Eletrônica em Gestão, Educação e Tecnologia Ambiental, v. 4, n. 4, p. 558-571, 2011.

ZABALZA, M. A. Diários de aula. Contributo para o estudo dos dilemas práticos dos professores. Porto: Porto Editora, 1994. 